\title{
PENGARUH ARUS PENGELASAN SS 304 MENGGUNAKAN SHIELDED METAL ARC WELDING (SMAW) TERHADAP KEKUATAN MEKANISNYA
}

\author{
Nidia lestari ${ }^{1}$, Bambang Wahyu Sidharta ${ }^{2}$, Arif Purnomo ${ }^{3}$ \\ 1,2,3 Jurusan Teknik Mesin, Fakultas Teknologi Industri, Institut Sains \& Teknologi Akprind Yogyakarta \\ 1nidianina14@akprind.ac.id \\ 2bwahyusidharta@yahoo.co.id \\ 3arifpur565@gmail.com
}

\begin{abstract}
Abstrak - AISI 304 merupakan baja yang memiliki kelebihan resistansi yang tinggi terhadap korosi dengan keuletan yang baik pada suhu yang relative rendah. Kelebihan tersebut, menjadikan AISI 304 Stainless Steel banyak digunakan pada industri otomtotif, sistem perpipaan, serta industry yang memiliki kontak dengan bahan kimia. Proses penyambungan pada bahan AISI 304 dapat dilakukan dengan Shielded Metal Arc Welding (SMAW), sehingga perlu diteliti untuk mengetahui bagaimana pengaruh arus listrik terhadap sifat mekanisnya. Elektroda yang digunakan adalah jenis E308-16 dengan variasi arus 90 ampere, 100 ampere, dan 110 ampere. Sifat mekanis diuji meliputi uji Tarik sesuai standar ASTM E8/E8M - 13 dan uji kekerasan sesuai standar ASTM E92-82 . Dari hasil penelitian menunjukkan bahwa faktor arus listrik dalam proses pengelasan SMAW sangat berpengaruh terhadap hasil pengelasan ditinjau dari kekuatannya. Kekuatan mekanis paling tinggi didapat pada pengelasan arus 110 ampere, dengan heat input sebesar $976,067 \mathrm{~J} / \mathrm{mm}$, kekuatan tarik ultimate rata-rata sebesar $68,438 \mathrm{~kg} / \mathrm{mm} 2$ untuk tegangan tarik dan regangan sebesar $47,451 \%$ pada pengujian tarik, dan nilai rata-rata kekerasan sebesar 225,008 HV untuk pengujian kekerasan pada daerah las.
\end{abstract}

Kata Kunci: SMAW; Stainless Steel 304; variasi arus; sifat mekanis

\begin{abstract}
AISI 304 is a steel that has the advantage of high resistance to corrosion with good ductility at relatively low temperatures. These advantages make AISI 304 Stainless Steel widely used in the automotive industry, piping systems, and industries that have contact with chemicals. The connection process on AISI 304 material can be done with Shielded Metal Arc Welding (SMAW), so it is necessary to research to find out how the effect of electric current on its mechanical properties. The electrodes used are E30816 types with current variations of 90 amperes, 100 amperes and 110 amperes. Mechanical properties tested include Tensile test according to ASTM E8 / E8M - 13 standards and hardness tests according to ASTM E92-82 standards. The results showed that the electric current factor in the SMAW welding process greatly influenced the welding results in terms of its strength. The highest mechanical strength was obtained at welding current of 110 amperes, with a heat input of $976.067 \mathrm{~J} / \mathrm{mm}$, an average ultimate tensile strength of $68.438 \mathrm{~kg} / \mathrm{mm} 2$ for tensile stress and strain of $47.451 \%$ in tensile testing, and an average hardness value of 225,008 HV for hardness testing in the weld area.
\end{abstract}

Keywords: SMAW; Stainless Steel 304; current variation; mechanical properties

\section{PENDAHULUAN}

Proses pengelasan Shielded Metal Arc Welding (SMAW) merupakan salah satu metode pengelasan menggunakan kawat elektroda logam yang berselaput fluks. Panas yang ditimbulkan dari busur listrik mencairkan ujung elektroda dan logam induk secara bersamaan. Elektroda yang mencair membentuk butirbutir logam cair yang terbawa arus listrik. Semakin tinggi arus listrik, maka butiran logam cair yang terbawa akan semakin halus. Butiran yang halus memberikan sifat mampu las logam yang tinggi. Pengujian sifat mekanis dapat memberikan informasi sifat mampu las logam[1].

Penelitian tentang variasi arus pengelasan SMAW telah banyak dilakukan. Salah satunya dengan memvariasikan arus yang digunakan 80 ampere, 90 ampere dan 100 ampere. Dari penelitian yang dilakukan dengan membandingkan hasil uji tarik antara spesimen yang tidak mengalami pengelasan dengan spesimen yang mengalami pengelasan. Dimana hasilnya adalah nilai tegangan tarik logam yang mengalami pengelasan lebih tinggi dibandingkan nilai tegangan tarik logam yang tidak mengalami pengelasan. Sedangkan untuk nilai kekerasan tertinggi terdapat pada daerah logam las dengan arus 80 ampere [2].

Besar dari arus listrik yang dibutuhkan dapat ditentukan dari ukuran elektroda, tebal spesimen las, bentuk sambungan, serta lokasi penyambungan. Adapun kisaran arus yang dapat digunakan sesuai dengan diameter elektroda terlihat pada Tabel I[3] 


\begin{tabular}{|c|c|c|c|}
\hline \multirow{2}{*}{$\begin{array}{l}\text { Electrode } \\
\text { Diameter, } \\
\text { in. }\end{array}$} & \multirow{2}{*}{$\frac{\text { Welding Current Amperes }^{\mathrm{A}}}{-15,-16,-17,-25,-26}$} & \multicolumn{2}{|c|}{$\begin{array}{l}\text { Approximate Dimensions of } \\
\text { Deposit, in. }\end{array}$} \\
\hline & & $w$ & $L$ \\
\hline $1 / 16$ & $35-50$ & 0.25 & $1-1 / 4$ \\
\hline $5 / 64$ & $45-60$ & 0.25 & $1-1 / 4$ \\
\hline $3 / 32$ & $65-90$ & 0.3 & $1-1 / 2$ \\
\hline $1 / 8$ & $90-120$ & 0.4 & $1-1 / 2$ \\
\hline $5 / 32$ & $120-150$ & 0.5 & $1-1 / 2$ \\
\hline $3 / 16$ & $160-200$ & 0.6 & $1-1 / 2$ \\
\hline $7 / 32$ & $200-240$ & 0.7 & $1-1 / 2$ \\
\hline $1 / 4$ & $240-280$ & 0.7 & $1-1 / 2$ \\
\hline
\end{tabular}

Stainless steel 304 merupakan bagian dari baja tahan karat austenite dengan paduan logam besi-krom-nikel dengan unsur utama 16-30 \% Krom (Cr) dan minimal $8 \%$ Nikel (Ni) dengan campuran unsur Molibdenum (Mo), Tembaga $(\mathrm{Cu})$, dan Mangan (Mn)[4].

\section{Masukan Panas (Heat Input)}

Energi panas pengelasan mempengaruhi kualitas hasil pengelasan. Energi panas dihasilkan dari tiga parameter yang meliputi kecepatan pengelasan (v) dalam $\mathrm{mm} / \mathrm{menit}$, arus las (I) dalam ampere, dan tegangan las (V) dalam volt. Hubungan antara ketiga parameter itu dapat dituliskan dalam persamaan berikut:

$$
H I=\frac{V \times I}{v} \times 60
$$

\section{Pengujian Tarik}

Uji Tarik dilakukan untuk mengetahui kekuatan tarik dari spesimen hasil pengelasan. Kekuatan tarik memberikan gambaran kualitas dari kekuatan las. Spesimen akan terdeformasi akibat pemberian gaya tarik dengan pembebanan yang diberikan secara kontinu dengan nilai yang semakin meningkat. Pengamatan pertambahan panjang diamati selama proses penarikan dilakukan. Gbr 1. Memperlihatkan hasil kurva hubungan besarnya pemberian tegangan terhadap regangan yang dialami spesimen

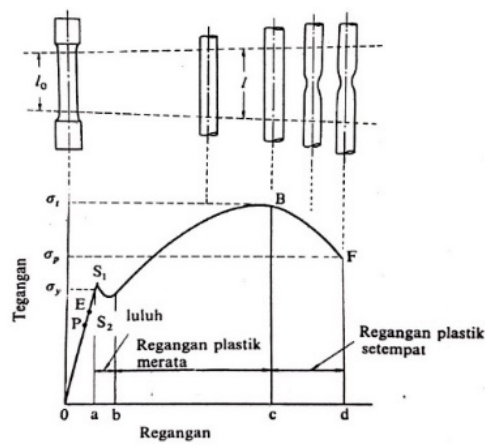

Gbr. 1 Kurva Tegangan-Regangan

Nilai tegangan dihitung dari hasil perbandingan antara beban dengan luas penampang awal spesimen.

$$
\sigma=\frac{P}{A}
$$

Keterangan:

$\sigma \quad$ : Tegangan nominal $\left(\mathrm{kg} / \mathrm{mm}^{2}\right)$

$\mathrm{P}$ : Beban maksimal $(\mathrm{kg})$

A : Luas penampang awal dari penampang batang $\left(\mathrm{mm}^{2}\right)$

Regangan (persentase pertambahan panjang) dapat dihitung dengan membagi perubahan panjang $(\Delta \mathrm{L})$ dalam mm dengan panjang ukur awal spesimen.

$$
\varepsilon=\frac{\Delta L}{L o} \times 100 \%=\frac{L-L o}{L o} \times 100 \%
$$

\section{Pengujian Kekerasan}

Uji kekerasan dilakukan untuk mengetahui kemampuan suatu bahan menerima beban yang terkonsentrasi pada permukaan. Nilai kekerasan bahan dapat dianalisis dari besarnya pembebanan yang diberikan terhadap luasan bidang yang menerima pembebanan.

Pengujian kekerasan dilakukan dengan mikro Vickers dengan penekan intan berbentuk piramida. Penekan ini menekan spesimen dengan beban tertentu hingga terjadi pembekasan tekanan seperti yang diperlihatkan Gbr 2 .

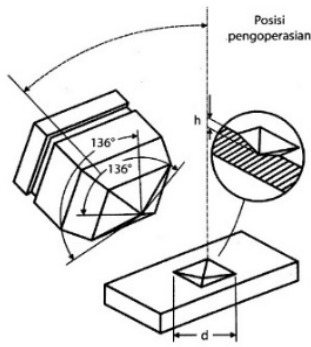

Gbr.2 Identor Piramid Intan Pada Metode Vickers

Nilai kekerasannya HV atau VHN (Vickers Hardness Number), didefinisikan sebagai beban identasi (P) dalam kg dibagi luas permukaan bekas penekanan dalam $\mathrm{mm}^{2}$.

$$
H V=\frac{\left[2 P \sin \left(\frac{136^{\circ}}{2}\right)\right]}{d^{2}}=\frac{1,854 P}{d^{2}}
$$

Nasrul, dkk. (2016) dalam penelitiannya memvariasikan arus las SMAW dan mengamati pengaruhnya terhadap kekerasan dan kekuatan Tarik sambungan dissimilar antara SS 304 dengan ST 37. Elektroda yang digunakan E 309 memberikan hasil meningkatnya nilai arus yang diberikan juga meningkatkan dari nilai kekerasan pada daerah logam las, dan nilai kekuatan tarik tertinggi terdapat pada pemberian arus sebesar 70 ampere[5].

\section{MATERIAL DAN METODE}

Material stainless steel 304 digunakan dalam penelitian ini dengan ukuran $600 \mathrm{~mm} \times 400 \mathrm{~mm} \times 6 \mathrm{~mm}$. Pengelasan dilakukan dengan memvariasikan besar arus 90 ampere, 100 ampere, dan 110 ampere. Penelitian dilakukan dengan prosedur sebagaimana dijelaskan pada Gbr 3. 


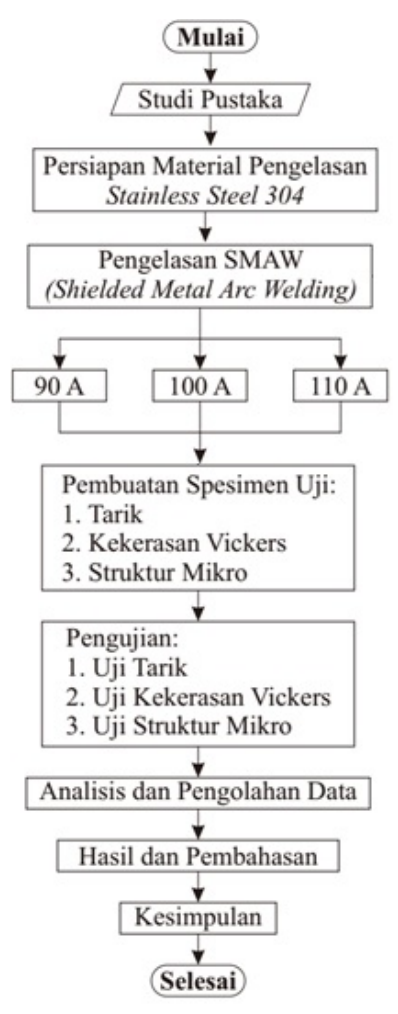

Gbr. 3 Diagram alir penelitian

\section{Persiapan Material Uji}

Material pelat stainless steel dipotong menjadi spesimen dengan ukuran $180 \mathrm{~mm} \times 110 \mathrm{~mm}$ sebanyak 6 lembar potongan, dengan bentuk yang ditunjukan pada Gbr 4 .

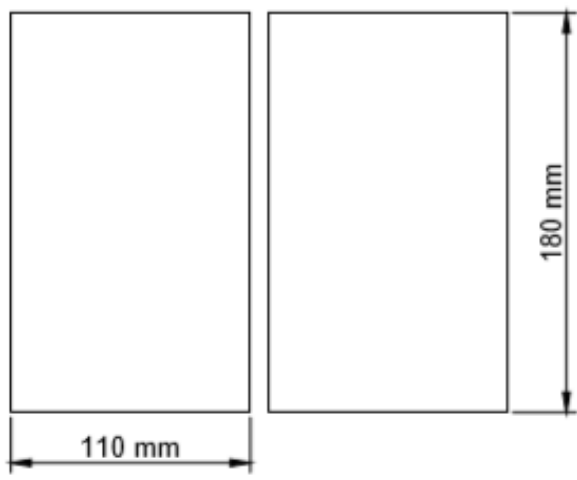

Gbr. 4 Dimensi spesimen pengelasan pelat SS

\section{Pembuatan Kampuh Las}

Kampuh las yang menggunakan sambungan las tumpul alur $\mathrm{V}$ tunggal dengan ketentuan celah akar $(\mathrm{G})$ sebesar $2 \mathrm{~mm}$, sudut alur (a) $60^{\circ}$, tebal (t) $6 \mathrm{~mm}$, dan c $2 \mathrm{~mm}$ yang terlihat pada gbr.5.

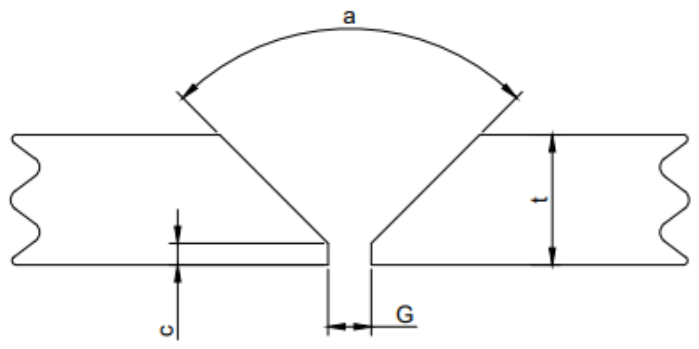

Gbr.5 Kampuh las single V-Joint

\section{Uji Tarik}

Jumlah spesimen setiap variable arus pengelasan adalah 5 spesimen, sehingga ada 15 spesimen total untuk uji tarik. Ukuran dimensi spesimen uji tarik mengikuti standar ASTM E8/E8M-13[6]. Ukuran spesimen yang telah disesuaikan dengan standar terlihat pada gbr. 6

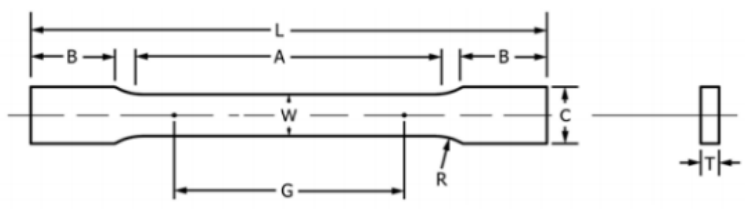

Keterangan:

$$
\begin{array}{lll}
\mathrm{L}=200 \mathrm{~mm} & \mathrm{~W}=12,5 \mathrm{~mm} & \mathrm{R}=12,5 \mathrm{~mm} \\
\mathrm{~A}=57 \mathrm{~mm} & \mathrm{G}=50 \mathrm{~mm} & \mathrm{~T}=6 \mathrm{~mm} \\
\mathrm{~B}=50 \mathrm{~mm} & \mathrm{C}=20 \mathrm{~mm} &
\end{array}
$$

\section{Uji Kekerasan}

Pengujian kekerasan dilakukan sebanyak 5 kali di setiap daerah dan dihitung nilai rata-rata kekerasan pada setiap daerah untuk dilakukan perbandingan. Skema uji kekerasan pada spesimen terlihat pada gbr.7. Dalam pengujian ini menggunakan standar ASTM E92-8[7]. Indentor intan berbentuk piramida dengan sudut $136^{\circ}$. Pengukuran panjang diagonal dilakukan dengan skala pada mikroskop.

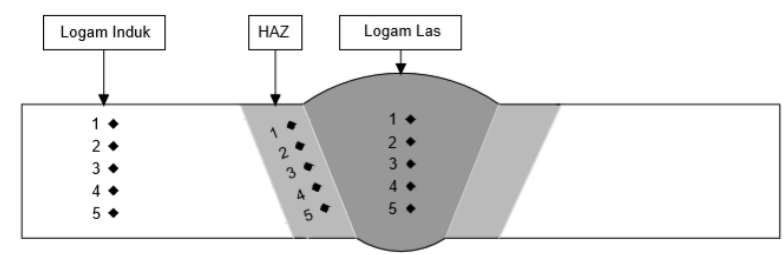

Gbr. 7 Skema uji kekerasan pada spesimen 


\section{HASIL DAN DISKUSI}

\section{Masukan Panas (Heat Input)}

Data yang diperoleh dari pengelasan kemudian dihitung untuk mendapatkan nilai masukan panas (HI) yang ditampilkan pada Tabel II.

Tabel II. Heat input

\begin{tabular}{|c|c|}
\hline Variasi Arus & Heat Input $(\mathrm{J} / \mathrm{mm})$ \\
\hline $90 \mathrm{~A}$ & 942 \\
\hline $100 \mathrm{~A}$ & 959 \\
\hline $110 \mathrm{~A}$ & 976,067 \\
\hline
\end{tabular}

Dari hasil yang ditampilkan pada table II, terlihat bahwa nilai heat input mengalami kenaikan. Busur listrik yang dihasilkan selama proses pengelasan dipengaruhi oleh besaran tegangan busur las, arus busur las, dan kecepatan las. Tegangan busur tidak memberi pengaruh yang besar terhadap HI, melainkan mempengaruhi manik las. Sedangkan Parameter arus las berpengaruh pada kecepatan pencairan logam induk dan ujung elektroda serta bentuk butirannya, dimana akan terjadi transformasi strukturmikro didaerah Heat affected zone (HAZ). Semakin besar heat input akan membuat daerah distribusi panas semakin besar karena masih ada daerah yang cukup luas untuk panas memperluas daerahnya akibat dari proses pengelasan berlangsung[8]

\section{Hasil Pengujian Uji Tarik}

Hasil yang diperoleh pada pengujian tarik disajikan pada table III:

\begin{tabular}{|c|c|c|c|c|}
\hline \multirow{2}{*}{ Parameter } & \multirow{2}{*}{ Spesimen } & \multicolumn{3}{|c|}{ Kuat Arus } \\
\hline & & $90 \mathrm{~A}$ & $100 \mathrm{~A}$ & $110 \mathrm{~A}$ \\
\hline \multirow{6}{*}{ Tegangan } & 1 & 68,222 & 68,102 & 67,861 \\
\hline & 2 & 55,358 & 67,834 & 68,484 \\
\hline & 3 & 67,424 & 66,777 & 68,534 \\
\hline & 4 & 66,790 & 67,121 & 68,356 \\
\hline & 5 & 64,011 & 66,037 & 68,954 \\
\hline & Rata-rata & 64,361 & 67,174 & 68,438 \\
\hline \multirow{6}{*}{ Regangan } & 1 & 44,939 & 47,727 & 50,828 \\
\hline & 2 & 34,208 & 45,248 & 49,126 \\
\hline & 3 & 44,231 & 47,469 & 41,259 \\
\hline & 4 & 48,351 & 44,164 & 46,655 \\
\hline & 5 & 33,508 & 44,328 & 49,388 \\
\hline & Rata-rata & 41,047 & 45,787 & 47,451 \\
\hline
\end{tabular}

Dengan memperhatikan table III. Nilai tegangan tarik tertinggi dari tiga variasi arus pengelasan 90 ampere, 100 ampere, dan 110 ampere yang tertinggi pada arus pengelasan 110 ampere sebesar $68,438 \mathrm{~kg} / \mathrm{mm}^{2}$.

Dalam pengujian tarik juga didapat nilai regangan sambungan Stainless Steel 304. Nilai rata-rata regangan tertinggi pada arus pengelasan 110 ampere sebesar 47,451\%. Nilai rata-rata regangan yang terjadi pada spesimen uji tarik membuktikan bahwa semakin besar kekuatan tarik suatu bahan maka semakin besar pula nilai regangan.

Hasil data yang diperoleh menunjukan besar arus pengelasan yang meningkat berbanding lurus dengan meningkatnya nilai tegangan dan regangan sambungan Stainless Steel 304 hasil pengelasan SMAW. Besar arus pengelasan mempengaruhi mudahnya elektroda mencair dan menyatu dengan dengan logam induk. Pada gbr. 8 ditampilkan hasil dari uji Tarik.

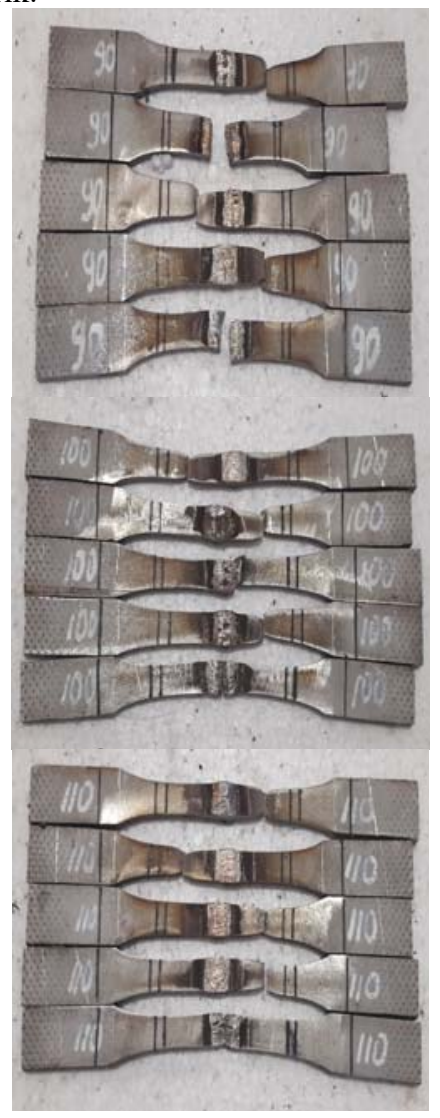

Gbr. 8 Spesimen Uji Tarik setelah pengujian

Terlihat bahwa spesimen yang paling banyak mengalami putus adalah hasil pengelasan dengan arus 90 ampere. Pada penyambungan dengan arus 100 ampere dan 110 ampere, putus terjadi tidak pada titik sambungan. Hal ini memeprlihatkan bahwa pemilihan arus juga mempengaruhi kualitas kekuatan sambungan las karena jika arus pengelasan yang digunakan terlalu rendah maka akan menghasilkan tingkat penetrasi yang kurang dalam. Untuk variasi arus 110 ampere pada penyambungan material stainless steel 304 dengan elektroda E308-16 memberikan hasil yang baik. Besarnya arus meningkatkan kemampuan las yang menjadikan elektroda yang mencair berpindah dalam bentuk butir-butir yang halus.

\section{Hasil Pengujian Uji Kekerasan}

Nilai kekerasan diukur dalam 3 daerah yaitu logam las, HAZ, dan logam induk, dimana masing-lokasi dilakukan pengukuran sebanyak 5 kali. Tiap daerah diberikan jarak, karena berkaitan dengan distribusi panas saat pengelasan. Terjadi peningkatan nilai kekerasan pada logam las dan terjadi penurunan nilai kekerasan pada daerah HAZ. Hal ini berkaitan dengan perubahan struktur mikro pada daerah yang terkena temperatur tinggi. Hasil yang diperoleh dari pengujian Kekerasan ditampilkan pada table IV: 
Tabel IV. Hasil Pengujian Kekerasan Vickers

\begin{tabular}{|c|c|c|c|c|}
\hline \multirow{2}{*}{ Arus } & \multirow{2}{*}{ Pengujian } & \multicolumn{3}{|c|}{ Kekerasan VHN } \\
\cline { 2 - 5 } & & Logam Induk & HAZ & Logam Las \\
\hline \multirow{4}{*}{ 90 A } & Titik 1 & 191,529 & 202,893 & 215,300 \\
\cline { 2 - 5 } & Titik 2 & 193,724 & 202,893 & 207,724 \\
\cline { 2 - 5 } & Titik 3 & 198,229 & 200,541 & 210,204 \\
\cline { 2 - 5 } & Titik 4 & 202,893 & 198,229 & 212,729 \\
\cline { 2 - 5 } & Titik 5 & 175,236 & 205,287 & 215,300 \\
\cline { 2 - 5 } & Rata-rata & 192,322 & 201,969 & 212,251 \\
\hline \multirow{4}{*}{ 100 A } & Titik 1 & 193,724 & 212,729 & 223,298 \\
\cline { 2 - 5 } & Titik 2 & 189,371 & 215,300 & 223,298 \\
\cline { 2 - 5 } & Titik 3 & 189,371 & 210,204 & 220,583 \\
\cline { 2 - 5 } & Titik 4 & 193,724 & 205,287 & 217,917 \\
\cline { 2 - 5 } & Titik 5 & 195,957 & 212,729 & 215,300 \\
\cline { 2 - 5 } & Rata-rata & 192,429 & 211,250 & 220,079 \\
\hline \multirow{4}{*}{ 110 A } & Titik 1 & 193,724 & 212,729 & 223,298 \\
\cline { 2 - 5 } & Titik 2 & 195,957 & 220,583 & 228,880 \\
\cline { 2 - 5 } & Titik 3 & 191,529 & 215,300 & 217,917 \\
\cline { 2 - 5 } & Titik 4 & 189,371 & 212,729 & 226,063 \\
\cline { 2 - 5 } & Titik 5 & 193,724 & 210,204 & 228,880 \\
\cline { 2 - 5 } & Rata-rata & 192,861 & 214,309 & 225,008 \\
\hline
\end{tabular}

Tabel IV menunjukan hasil uji kekerasan hasil pengelasan SMAW dengan arus 90 ampere, 100 ampere, dan 110 ampere, kemudian di gambarkan grafik hubungan antara variasi arus untuk mengetahui nilai kekerasan dari tiap arus yang ditunjukan pada gbr.8.

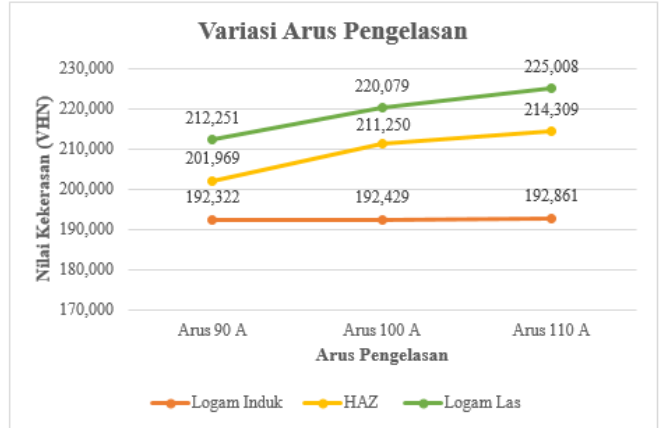

Gbr.8 Hubungan nilai kekerasan arus Pengelasan

Hasil pengujian pada daerah logam induk dengan variasi arus pengelasan didapat nilai rata-rata kekerasan hampir seragam yaitu $192,322 \mathrm{HV}, 192,429 \mathrm{HV}$, dan 192,861 HV, karena saat proses pengelasan pada daerah logam induk tidak mengalami siklus termal sehingga tidak mengalami perubahanperubahan struktur mikro dan sifat mekanisnya. Hal ini dikarenakan pada daerah logam induk tidak terjadi transformasi fasa.

Pada variasi arus pengelasan untuk daerah HAZ mengalami peningkatan nilai rata-rata kekerasan. Nilai kekerasan arus awal pengelasan 90 ampere sebesar 201,969 HV menjadi 211,250 HV pada arus 100 ampere, kemudian pada arus 110 ampere nilai kekerasan mengalami peningkatan kembali menjadi 214,309 HV. Hal ini membuktikan bahwa daerah HAZ yang mengalami perubahan fasa karena adanya siklus termal pemanasan dan pendinginan cepat. Variasi arus pengelasan yang semakin meningkat berbanding lurus dengan nilai kekerasan karena arus yang besar akan mengeluarkan energi panas yang besar pula.
Pada daerah las memiliki nilai rata-rata kekerasan tertinggi dibandingkan dengan daerah logam dan HAZ. Hal ini dikarenakan elektroda yang digunakan E308-16 memiliki kandungan unsur $\mathrm{Si}, \mathrm{S}, \mathrm{Cr}$ dan $\mathrm{Ni}$ yang lebih tinggi dari kandungan pada stainless steel 304. Kandungan unsur tersebut pada stainless steel akan meningkatkan nilai kekerasan terhadap bahan tersebut. Arus pengelasan juga berperan bahwa arus yang semakin besar mengakibatkan proses pencairan logam induk dan elektroda lebih cepat sehingga menghasilkan kandungan unsur kimia pada sambungan las yang baik. Nilai rata-rata kekerasan tertinggi terdapat pada daerah logam las dengan arus 110 ampere sebesar 225,008 HV kemudian disusul arus 100 ampere sebesar 220,079 dan nilai rata-rata kekerasan terendah pada arus 90 ampere sebesar 212,251 HV.

\section{KESIMPULAN}

Dari hasil penelitian dan pembahasan tentang pengaruh arus pengelasan SS 304 menggunakan shielded metal arc welding (smaw) terhadap kekuatan mekanisnya maka dapat disimpulkan sebagai berikut :

1. Dari variasi arus pengelasan SMAW pada SS 304 dengan arus pengelasan 90 ampere, 100 ampere, dan 110 ampere didapat masukan panas (heat input) tertinggi pada arus 110 ampere sebesar 976,067 J/mm, sedangkan nilai masukan panas terendah pada arus 90 ampere sebesar 942 $\mathrm{J} / \mathrm{mm}$.

2. Sifat mekanis sambungan las SS 304 adalah sebagai berikut :

a. Nilai rata-rata tegangan tarik tertinggi terdapat pada pengelasan dengan arus 110 ampere sebesar 68,438 $\mathrm{kg} / \mathrm{mm}^{2}$ dan nilai rata-rata tegangan tarik terendah terdapat pada pengelasan dengan arus 90 ampere sebesar $64,361 \mathrm{~kg} / \mathrm{mm}^{2}$. Untuk regangan tarik didapat nilai tertinggi pada arus 110 ampere sebesar $47,451 \%$ dan terendah pada arus 90 ampere yaitu $41,047 \%$.

b. Nilai rata-rata kekerasan tertinggi terdapat pada spesimen dengan variasi arus 110 ampere sebesar 225,008 HV dan nilai rata-rata kekerasan terendah yaitu pada arus 90 ampere sebesar 212,251 HV

\section{UCAPAN TERIMA KASIH}

Penulis ucapkan terima kasih kepada Lembaga Penelitian dan Pengabdian kepada masyarakat (LPPM) Institut Sains \& Teknologi atas bantuan dana yang telah diberikan, sehingga penelitian ini dapat berjalan lancar.

\section{REFERENSI}

[1] Wiryosumarto, H dan Toshie Okumura. (2004). Teknologi Pengelasan Logam. Cetakan Kesembilan. Jakarta: Pradnya Paramita.

[2] Azwinur, A., Jalil, S. A., \& Husna, A. (2017). Pengaruh variasi arus pengelasan terhadap sifat mekanik pada proses pengelasan SMAW. Jurnal POLIMESIN, 15(2), 36-41.

[3] AWS A5.4. 1992. Specification for Stainless Steel Electrodes for Shielded Metal Arc Welding. Miami: American Welding Society Inc.

[4] ASM Handbook Vol 9. (2004). Metallography And Microstructure. ASM 
[5] Nasrul, M. Yogi, Suryanto, H., \& Qolik, A. (2016). Pengaruh Variasi Arus Las SMAW Terhadap Kekerasan dan Kekuatan Tarik Sambungan Dissimilar Stainless Steel 304 dan ST 37. JURNAL TEKNIK MESIN, 24(1).

[6] ASTM E8/E8M - 13. (2013). Standard Test Methods for Tension Testing of Mettalic Materials. United States: ASTM International.

[7] ASTM E92-82. (1997) Standard Test Methods for Vickers Hardness of Mettalic Materials. United States: ASTM International.

[8] Ismail, Andhanu S. (2015). Analisa Pengaruh Variasi Heat Input dan Temperatur PWHT terhadap Struktur Mikro dan Sifat Mekanik pada Baja Paduan rendah dengan Proses Pengelasan SMAW. Tugas akhir, Institut Teknologi Sepuluh November. 